\title{
Analysis on the Modes and Characteristics of the Renovation of Rural Human Settlements in Yunnan in the New Era
}

\author{
Deng Min ${ }^{*}$, Liu Yan, Yan Peisheng, Yang Xiucui \\ Faculty of Geography Science and Tourism, Zhaotong University, Zhaotong, Yunnan, 657000, \\ China
}

Keywords: Yunnan; rural residents; new urbanization; policy cognition

\begin{abstract}
Promoting new urbanization is an important strategy for China's economic and social development. It is more strategic for ethnic areas with relatively lagging economic and social development. However, whether the new urbanization policy can be implemented smoothly depends largely on the rural residents in ethnic areas. According to a questionnaire survey conducted by rural residents in Yunnan Province, although rural residents have a strong demand for understanding new urbanization policies, the actual cognitive channels are limited, resulting in a low level of actual understanding of relevant policies. It is necessary to increase the propaganda of new urbanization policies, select effective ways to choose, reform the propaganda content, and rectify the rural human settlements in Yunnan.
\end{abstract}

\section{Introduction}

The policy of "rescue the disease with awards" in rural environmental protection is an important measure to promote the construction of ecological civilization, an important means to protect people's livelihood, an urgent need to realize the task of coordinating urban and rural development, and a major policy innovation in environmental protection ${ }^{[1]}$. However, due to insufficient attention to this work in some places, the grassroots environmental protection departments have not understood and grasped the policy deeply, and the guidance and supervision of the project implementation have been weak. The implementing units have not implemented strictly according to procedures and requirements, and the funds used in some projects have been Management is not standardized. In order to effectively strengthen rural environmental protection, deepen the policy of "promoting governance with awards", standardize the management of central rural environmental protection and provincial-level environmental protection special fund projects, and ensure the effectiveness of the implementation of rural environmental comprehensive improvement projects ${ }^{[2]}$.

\section{The significance and foundation of Yunnan's ecological province construction}

\subsection{The Necessity and Importance of the Renovation of Rural Human Settlements in Yunnan}

On October 15, 2017, the General Secretary, on behalf of the 16th CPC Committee, made a 
report to the 17th National Congress of the Communist Party of China, "Building an ecological civilization, basically forming an industrial structure, a growth model, and consumption model for saving energy resources and protecting the ecological environment" ${ }^{[1]}$. One of the goals of building a well-off society, the concept of "ecological civilization" was first written into the political report of the party congress. The minimum radius of the flat curve of the village road shall comply with the provisions of Table 1; the minimum radius of the intersection edge stone shall comply with the provisions of Table 2:

Table 1: Minimum radius of flat curve of Yunnan village road

\begin{tabular}{ccc}
\hline Design speed $(\mathbf{k m} / \mathbf{h})$ & $\mathbf{3 0}$ & $\mathbf{2 0}$ \\
\hline General value $(\mathbf{m})$ & 65 & 30 \\
Limit value $(\mathbf{m})$ & 30 & 15 \\
\hline
\end{tabular}

It will make a fundamental shift in the shape of human society. The ecological environment is a direct response to the achievements of ecological civilization construction. Carrying out the construction of the ecological province is an important starting point for the construction of ecological civilization ${ }^{[2]}$.

Table 2: Minimum radius of the intersection of the village road

\begin{tabular}{cccc}
\hline Turn right to calculate driving speed (km/h) & $\mathbf{2 0}$ & $\mathbf{1 5}$ & $\mathbf{1 0}$ \\
\hline Crossing edge stone turning minimum radius (m) & $10 \sim 15$ & $5 \sim 10$ & $3 \sim 5$ \\
\hline
\end{tabular}

In the range of the line of sight of the village's primary and secondary road intersections, there shall be no structures or other obstacles that obstruct the driver's line of sight. If there is greening, the height shall be no more than $0.7 \mathrm{~m}$. The minimum parking distance is shown in Table 3:

Table 3: Parking Sights in Yunnan Village Habitat Environment ${ }^{[2]}$

\begin{tabular}{cccccc}
\hline Calculate the driving speed $(\mathbf{k m} / \mathbf{h})$ & $\mathbf{3 0}$ & $\mathbf{2 5}$ & $\mathbf{2 0}$ & $\mathbf{1 5}$ & $\mathbf{1 0}$ \\
\hline Parking line of sight $(\mathbf{m})$ & 30 & 25 & 20 & 15 & 10 \\
\hline
\end{tabular}

In addition to the road traffic requirements shown in Tables 1, 2 and 3 above, ecological civilization refers to the synthesis of material-spiritual achievements obtained by human beings following the objective law of harmonious development of human, nature and society; it refers to man and nature, The cultural ethics of the basic purpose of harmony between human beings, people and society, virtuous circle, all-round development and sustained prosperity.

The remarkable achievements of the pilot provinces and cities in the construction of domestic ecological provinces have shown that the construction of ecological provinces promotes sustainable development and solutions. The contradiction between economic development and environmental protection has great vitality. Yunnan's natural resource advantages and the severe environmental forms it faces are demanding that Yunnan must follow the path of ecological province construction [3]

\subsection{Yunnan is a key area for the protection of animal and plant resources in China}

Yunnan's unique natural geographical environment has enriched the resources of species, and its biological rich value, unique value and unique rate account for the first place in the country. Yunnan has vertebrate animals and key protected wild animals, accounting for $54.8 \%$ and $59.4 \%$ of the total, respectively, and more than half of them, and about $15 \%$ of the total species are unique to Yunnan or only found in Yunnan. Therefore, in the rural human settlements environment politics in Yunnan, the choice of water source should meet the following requirements: 
- The water quantity is sufficient; the water source has good sanitary conditions and is convenient for sanitary protection ${ }^{[1]}$;

- The quality of raw water meets the requirements, and groundwater is preferred;

- Water, clean water, water distribution and distribution facilities are safe and economical, and have construction conditions ${ }^{[3]}$;

- When groundwater is selected as the source of water supply, it shall not be over-exploited. When surface water is selected as the source of water supply, the guarantee rate of dry season shall not be less than $90 \%$.

- The water source is preferably in a higher position to achieve self-flowing water or full-automatic water supply ${ }^{[4]}$;

- When the water quality, water quantity and water source position can meet the requirements, the order of water source selection depends on: spring water, reservoir water, well water and river water.

There are more than 18,000 higher plants in Yunnan, accounting for 51.6\% of the total number of the country; among the 352 protected rare and endangered plants announced by the state, there are 151 species in Yunnan, accounting for $42.6 \%$ of the total number of protected plants in the country. Yunnan is not only rich in species diversity, but also possesses a very high proportion of rare and endangered species and endemic species. It is a high-frequency region of endemic plants in China. There are 243 seed plants in China, and 180 Chinese endemic genera in Yunnan, accounting for China. $74.1 \%$ of the unique genera, 30 of which are unique to Yunnan Province. It can be seen that the biodiversity resources owned by Yunnan is one of the natural gene banks rich in biological genetic material in China and the world. It has important scientific, economic, environmental and aesthetic values. The protection of Yunnan's ecological environment is for China. And the protection of the world's biodiversity is extremely important and has an important position ${ }^{[4]}$.

\subsection{Yunnan's biological resources play an important role in the sustainable development of Yunnan's social economy}

Biological resources are not only the advantages of Yunnan's development, but also the new economic growth point with the greatest potential and prospects. The Yunnan Provincial Party Committee and the provincial government have proposed to build Yunnan into a green economy and a major tourism province. However, more and more studies have shown that with the development of the economy, the species resources bred by Yunnan's unique geographical environment are facing great threats as the ecological environment is deteriorating. If the ecological environment of Yunnan is destroyed, biodiversity will disappear, and Yunnan's resource advantages will If it no longer exists, the bio-industry and tourism industries will become the rootless and passive water, which will seriously restrict the sustainable development of Yunnan's economy.

\section{Countermeasures for Yunnan to carry out ecological province construction}

\subsection{Strengthen organizational leadership and clarify the division of responsibilities}

The main responsibility of the rural environmental comprehensive improvement project is the county-level people's government. The main body of implementation is the township people's government. The environmental protection and finance departments are responsible for the implementation and supervision of the project implementation. The people's governments at the county level shall strengthen organizational leadership, integrate the agriculture-related funds of relevant departments, clarify responsibilities, and implement them at all levels ${ }^{[3]}$. 


\subsection{Strictly implement the procedures and conscientiously implement the system}

The rural environmental comprehensive improvement project implements five systems: responsibility system, reporting system, county-level financial reporting system, publicity system and farmer participation system. The responsibility for the comprehensive improvement of the rural environment lies mainly in the localities, and the people's government at the county level is the main body of responsibility. Within 20 working days after the provincial finance budget is issued, the county-level people's government shall organize the completion of the revision and improvement of the project implementation plan, report it to the provincial (city) level environmental protection and financial department for approval, and report it to the provincial environmental protection and finance department for the record. . Among them, the water supply pipe can be selected from PE water supply plastic pipe, ductile iron pipe and galvanized steel pipe. When the water source, water transmission line topographic conditions, transportation and secondary handling conditions permit, self-stressed reinforced concrete pipes and pressurised reinforced concrete pipes may also be used; and the pipe diameter of the water pipe shall be determined by calculation ${ }^{[1]}$. The water pipe diameter is generally calculated using the following formula:

$$
f(x)=a_{0}+\sum_{n=1}^{\infty}\left(a_{n} \cos \frac{n \pi x}{L}+b_{n} \sin \frac{n \pi x}{L}\right)
$$

Where: $f(x)$-water pipe diameter $(\mathrm{m})$

$a_{0}$-Flow at the highest daily maximum condition (m3/S)

$\mathrm{X}$-flow rate $(\mathrm{m} / \mathrm{S})$

In the design, the economic flow rate is used to control the head loss value of the pipe section (generally about $5 \mathrm{~m} / \mathrm{Km}$ ) to determine the economic pipe diameter. When determining the economic flow rate based on this head loss control value, the economic flow rate value is:

- When $\mathrm{d}=100 \sim 350 \mathrm{~mm}, \mathrm{~V}_{\mathrm{e}}$ adopts $0.50 \sim 1.10 \mathrm{~m} / \mathrm{S}$;

- When $\mathrm{d}=350 \sim 600 \mathrm{~mm}, \mathrm{~V}_{\mathrm{e}}$ adopts $1.10 \sim 1.60 \mathrm{~m} / \mathrm{S}$;

When $\mathrm{d}=600 \sim 1000 \mathrm{~mm}, \mathrm{~V}_{\text {e }}$ adopts $1.60 \sim 2.00 \mathrm{~m} / \mathrm{S}^{[4]}$.

The special funds shall implement the county-level financial reimbursement system. The county-level financial and environmental protection departments shall strengthen the review and management of the special fund disbursement work to ensure the earmarking and special accounting, and shall not intercept, occupy or misappropriate. Villages and towns supported by special funds shall, in accordance with the requirements of government affairs disclosure, announce the details of the special fund arrangement and use, project arrangements and specific implementation conditions to the farmers in the beneficiary areas. Where conditions permit, the relevant situation should be announced on the government's portal of the Ministry of Finance and Environmental Protection to accept social supervision. In order to fully mobilize the enthusiasm and creativity of farmers and respect the wishes of farmers, farmers should be encouraged to participate in the formulation of project implementation plans and supervision of funds during the implementation of the project, and encourage farmers to invest in labour ${ }^{[4]}$.

\subsection{Scientifically formulate programs and strengthen technical guidance}

In the process of preparing the project implementation plan, the technical unit should conscientiously study the "promoting the award with awards" and the rural environmental protection policy, and combine the actual situation of each place, and fully refer to the opinions of the grassroots departments and farmers to formulate practical and feasible plans. Once the rural environmental comprehensive improvement project plan has been reviewed and approved, it shall 
not be adjusted in principle, and the objectives of the governance target shall not be reduced, and the scale of investment shall be reduced. If it is necessary to adjust, it must be reported to the provincial environmental protection and financial department for approval before implementation. The technical units of the project preparation units are responsible for the implementation and operation of the project, and the municipal and county environmental protection departments should also strengthen the contact with the programming unit to ensure that the project implementation meets the design requirements of the project.

\section{Conclusion}

After investigation and analysis, we can find that the rural environmental protection policy of "promoting and treating with awards" is an important measure to promote the construction of ecological civilization, an important means to protect people's livelihood, an urgent need to realize the task of coordinating urban and rural development, and a major policy innovation in environmental protection. Since the implementation of the policy of "promoting the award with awards" by the central government in 2008, a number of outstanding environmental problems have been resolved in a number of people in the province. The villages and villages in many villages have been significantly improved, and some projects have achieved the unification of ecological, social and economic benefits. In the new era, the rural residential environment improvement model in Yunnan has been continuously optimized and developed.

\section{Acknowledgements}

(1) A Study on the Protection and Exploitation of the Ecological Environment in Zhaotong in New Era(zt2019002)

(2) A Study on the County Economy in Northeast of Yunnan Province under the Background of All-for-One Tourism(2018JS509)

\section{References}

[1] Jing T, Xie Y. Research on the architecture and strategies of Yunnan rural human resources smart development in the era of big data[C]// International Conference on Information Management. 2017.

[2] Huang Z. The Research of SDN Group Policy Model Based on Application Centric Environment[C]// Sixth International Conference on Intelligent Systems Design \& Engineering Applications. 2016.

[3] Liang E, Wang Y, Piao S, et al. Species interactions slow warming-induced upward shifts of treelines on the Tibetan Plateau.[J]. Proceedings of the National Academy of Sciences of the United States of America, 2016, 113(16):4380-4385.

[4] Jing T, Zheng Z. Smart education in Yunnan, China: Present situation and construction measures[C]// International Conference on Service Systems \& Service Management. 2017. 